OPINION PIECE

\title{
Increasing Representation and Equity in Students as Partners Initiatives
}

\author{
Gagandeep Bindra ${ }^{a}$, Kirthika Easwaran ${ }^{a}$, Lamia Firasta ${ }^{a}$, Monika Hirsch ${ }^{a}$, *Aakriti Kapoor ${ }^{b}$, \\ Alexandra Sosnowski ${ }^{a}$, Taleisha Stec-Marksman ${ }^{a}$, and Gizem Vatansever ${ }^{a}$ \\ aDepartment of Psychology, University of Toronto Scarborough, Canada \\ ${ }^{b}$ Master of Teaching, Ontario Institute for Studies in Education, Canada \\ Contact: aakritikapoor09@gmail.com
}

Note: To avoid inequitable hierarchies and power structures among students and staff, the author order for this publication was purposely presented alphabetically instead of through typical authorship conventions.

\author{
"Knowledge is power," he says, \\ Yet knowledge is held in the hands of few. \\ And so is power. \\ The man who gets all the credit, \\ The privileged, and wealthy, and western man, \\ Who thinks everyone else is unfit, \\ And still won't admit, that \\ Knowledge should not mean power \\ But empowerment for all. \\ - Taleisha Stec-Marksman
}

We are all students at the University of Toronto's Scarborough campus, which is situated in one of the most multicultural neighbourhoods of Toronto (University of Toronto Scarborough, 2018), and possibly all of Canada. Aakriti Kapoor is a graduate student in the Faculty of Education, while most of the other authors are students whom Aakriti taught while working as a teaching assistant at the university. We come from a diverse range of racialized or gendered identities and abilities. We have all directly been impacted by or witnessed the damaging effects of colonialism and Western hegemony. As such, we hold a heightened sense of urgency to dismantle broader power structures in society, be they related to race, gender, age, sex, experience, or anything else in between. Power structures can be especially evident in student-faculty relationships, but as has already been noted in the past, Students as Partners (SaP) initiatives hold the potential to eliminate such tensions (Reyes \& Adams, 2017). In this 
paper, we discuss opportunities where SaP can further break down inequitable relationships to allow all students a better chance of success.

We reviewed publications from the International Journal for Students as Partners (IJSaP) (Vol. 1, No. 1 \& 2, 2017) and the special section on "Students as Co-Inquirers" in Teaching \& Learning Inquiry (TLI) (Vol. 4, No. 2, 2016). Grounded in our review and our first-hand experiences as students, this opinion paper discusses current SaP initiatives from the context of missing voices. Much of SaP as currently practised operates primarily in the west ${ }^{1}$ or the Global North. ${ }^{2}$ We question inequities surrounding this issue and aim to contribute to an emerging conversation about how the inclusion of diverse perspectives can transform SaP. We discuss how SaP can be more inclusive of non-western institutions as a means to address system-wide inequity, namely by being more inclusive of countries in the Global South. SaP is a global initiative. However, to be a truly global initiative in practice, it would need to better understand how other nations such as India, Kenya, Chile, and Mozambique would understand SaP. Would SaP even apply there? How might other countries look at SaP differently? How might we benefit from learning about cross-cultural approaches to how students can become partners in education? We continue this thread by discussing which students are often not given the opportunity to become partners in SaP initiatives, and how that perpetuates existing systemic inequity.

Publications from the IJSAP and TLI are mostly from Australia, United States, Canada, United Kingdom, or other western nations. Goldsmith, Hanscom, Throop, and Young (2017), in particular, speak to the need to include more diverse voices in SaP, yet there is no mention of how this can be done on an international level. The IJSaP international advisory board, for example, has advisors from a wide range of countries; however, these advisors too are limited to USA, Canada, United Kingdom, Hong Kong, Singapore, Australia, and Sweden. These are all predominantly countries from the Global North, and do not represent a truly international worldview encompassing South American, African, Middle Eastern, or Asian countries. The lack of global voices not only reinstates western dominance of ideas, but also could prevent SaP from deeply embodying culturally relevant, decolonized practices. If we want SaP to become more equitable, it must become more representative and accessible to non-western institutions. For example, journals like IJSaP can possibly address this limitation by reaching out to a greater number of post-secondary institutions in countries outside of the Global North. Reaching out to scholars in countries like Brazil, India, Pakistan, or Egypt, to name a few, and asking them to serve as reviewers, or help us consider SaP from a cross-cultural lense is one small way SaP can become more representative. In this attempt, we have to be careful to not push SaP on countries that might not want to adopt this initiative, but we should still try to look at more perspectives from the Global South to understand SaP in new ways.

Reyes and Adams (2017) show that SaP programs have the power to make learning spaces more equitable, but a scan of current SaP initiatives raises the question whether SaP fully brings all student voices to the forefront. Many SaP projects rely on student volunteers: students have the option to become partners if they choose to participate in the activities available to them (Werder, Thibou, Simkins, Hornsby, Legg, \& Franklin, 2016). Alternatively, some SaP projects select student-partners based on grade point averages (GPAs), resumes, and cover letters (Oleson \& Hovakimyan, 2017). Does this then include struggling or marginalized 
students? Are students who are failing classes or those who do not have time for extracurricular involvement (Marquis, Jayaratnam, Mishra, \& Rybkina, 2018) capable of becoming equal partners in education? Dwyer (2018) explains SaP can take on a neoliberal process, which favours high achieving students, and when SaP participation is unpaid or the pay-to-work ratio is unbalanced, SaP can further only favour students who are financially stable or who can manage the extra workload. It is important to consider that students who are struggling may also share intersectional identities relating to race, mental health, ability, gender, sex, or more, which can perpetuate a cycle of systemic inequity more broadly. For example, due to less access to academic educational opportunities, racialized students may at times have lower-than-average GPAs, higher identification of special education needs, or lower likelihoods of taking academic-stream courses than white students (Robson, Anisef, Brown, \& George, 2018). Alternatively, a student living with mental illness may struggle to balance academic responsibilities and do poorly in their classes if they do not receive adequate support (Shor, 2017). If SaP prioritizes high-achieving students, then it must also question to what extent that favouring perpetuates systemic privilege and inequity.

This may require staff to continue reimagining what they define as success and talent: how can staff aim to use different strategies to better understand the ideas of students who don't appear to be star students. For example, this paper was written by a lead graduate student and her undergraduate students. The undergraduate students did not need to have prior research experience or high GPAs-anyone and everyone was welcome to join. This, however, did require the lead graduate student to put in more time coordinating the project and facilitating the development of younger students on the team. Even though some writers put in more time than others, what mattered more was that the ideas of all students were considered in the creation of this publication.

Matthews $(2016 ; 2017)$ emphasizes SaP's risk of appropriation for neoliberal purposes, where SaP goes from a relational process to one focused entirely on outcomes of student satisfaction). When this happens, "the language of SaP is adopted, while the practices become 'watered down'” (Matthews, 2017, p. 5). Yet, a focus on collaboration that dismantles hierarchies of power while actively engaging institutions and students from all cultural backgrounds, class, and social positioning is one that also has the power to create learning models that empower every single student (Matthews, 2016; 2017). We, the students of Scarborough, call the SaP community to think critically about its current practices as to who is involved in shaping the dialogue. Whose perspectives are missing? More importantly, how can SaP be transformed if it relies on partnerships that come from competing worldviews?

Students should be As partners.

But it looks more like

The Privileged,

Get to be partners.

More than equity

Are we favouring hegemonic power? 
We can claim our voices in

Articles.

Opinions.

Journals.

But how many voices will it take?

To break this power?

This

Power

Of educator over student

of neoliberal capital

of profit over human connection

When will education be for the

Greater Good?

And not just some overpriced textbook?

When will education benefit,

Not just professors and students

But the whole World!

- Lamia Firasta

\section{ACKNOWLEDGEMENTS}

To the students and stories of Scarborough.

\section{NOTE}

1. We purposely decided not to capitalize west to avoid giving it this importance in the context of the paper's discussion.

2. Global North refers primarily to nations in North America, Europe, Australasia, and developed parts of East Asia. These nations disproportionately control global resources in terms of wealth, housing, education, digital media access, and numerous other factors, while actively excluding countries in the Global South, which are home to the majority of the world's natural resources and population (Guzzetti \& Lesley, 2015).

\section{NOTE ON CONTRIBUTORS}

Gagandeep Bindra is a third-year undergraduate student pursuing a specialist in psychology at the University of Toronto Scarborough.

Kirthika Easwaran is a fourth-year undergraduate student pursuing a specialist in mental health studies at the University of Toronto Scarborough. 
Lamia Firasta is a third-year undergraduate psychology student at the University of Toronto Scarborough, and hopes to pursue therapy and counselling in the future.

Monika Hirsch is a third-year undergraduate student pursuing a specialist in mental health studies at the University of Toronto Scarborough. Monika also plays varsity rugby for the university.

Aakriti Kapoor recently graduated with a Master of Teaching degree from the University of Toronto and an Honours Bachelor of Science from the University of Toronto Scarborough. She currently works as the Administrative and Research Coordinator at People for Education.

Alexandra Sosnowski is a fourth-year undergraduate student pursuing a specialist in mental health studies at the University of Toronto Scarborough.

Taleisha Stec-Marksman is a third-year undergraduate student pursuing a specialist in mental health studies at the University of Toronto Scarborough. Taleisha's research interests include emotion and relationships.

Gizem Vatansever is a fourth-year undergraduate student pursuing a specialist in mental health studies at the University of Toronto Scarborough, and hopes to pursue clinical psychology in the future. Gizem's research interests include studying psychosocial factors that may pose barriers for students facing mental health struggles.

\section{REFERENCES}

Goldsmith, M., Hanscom, M., Throop, S., \& Young, C. (2017). Growing student-faculty partnerships at Ursinus College: A brief history in dialogue. International Journal for Students as Partners, 1(2). http://dx.doi.org/10.15173/ijsap.v1i2.3075

Dwyer, A. (2018). Toward the formation of genuine partnership spaces. International Journal for Students as Partners, 2(1), 11-15. https://doi.org/10.15173/ijsap.v2i1.3503

Guzzetti, B., \& Lesley, M. (2015). Handbook of Research on Societal Impact of Digital Media. Hershey, PA: IGI Global.

Marquis, E., Jayaratnam, A., Mishra, A., \& Rybkina, K. (2018). “I feel like some students are better connected": Students' perspectives on applying for extracurricular partnership opportunities. International Journal for Students as Partners, 2(1), 64-81. https://doi.org/10.15173/ijsap.v2i1.3300

Matthews, K. E. (2016). Students as partners as the future of student engagement. Student Engagement in Higher Education Journal, 1(1), 1-5.

Matthews, K. E. (2017). Five propositions for genuine students as partners practice. International Journal for Students as Partners, 1(2). http://dx.doi.org/10.15173/ijsap.v1i2.3315

Oleson, K., \& Hovakimyan, K. (2017). Reflections on developing the student consultants for teaching and learning program at Reed College, USA. International Journal for Students

Bindra, G., Easwaran, K., Firasta, L., Hirsch, M., Kapoor, A., Sosnowski, A., Stec-Marksman, T., \& 
as Partners, 1(1). http://dx.doi.org/10.15173/ijsap.v1i1.3094

Reyes, V., \& Adams, K. (2017). Navigating a difficult journey: Reflections on how a studentfaculty partnership helped address racial tensions in a social science course. International Journal for Students as Partners, 1(2). http://dx.doi.org/10.15173/ijsap.v1i2.3262

Robson, K., Anisef, P., Brown, R.S., \& George, R. C. (2018). Under-represented students and the transition to post-secondary education: Comparing two Toronto cohorts. Canadian Journal of Higher Education, 48(1). Retrieved from http://journals.sfu.ca/cjhe/index.php/cjhe/article/view/187972/pdf

Shor, R. (2017). Difficulties experienced by university students with severe mental illnesses who participate in supported education programs. Community Mental Health Journal, 53, 281-287.

University of Toronto Scarborough. (2018). University of Toronto Scarborough at a Glance. Retrieved from https://www.utsc.utoronto.ca/aboutus/university-toronto-scarboroughglance

Werder, C., Thibou, S., Simkins, S., Hornsby, K., Legg, K., \& Franklin, T. (2016). Co-inquiry with students: When shared questions lead the way. Teaching \& Learning Inquiry: The ISSOTL Journal, 4(2). http://dx.doi.org/10.20343/teachlearninqu.4.2.4 